\title{
Seismic analysis of interlocking mortarless hollow block
}

\begin{abstract}
Various types of interlocking mortarless (dry-stacked) block masonry systems have been developed worldwide. However, the characteristics of dry joints under compressive load, and their effect on the overall behavior of the interlocking mortarless system, are still not well understood. This paper presents an investigation into the dry-joint contact behavior of masonry and the behavior of interlocking mortarless hollow blocks wall construction subjected to seismic excitation. In the system developed, the blocks are stacked on one another and three-dimensional interlocking protrusions are provided in the blocks to integrate the blocks into walls. The response of the mortarless hollow block wall with respect to acceleration displacement and stress have been discussed.
\end{abstract}

Keyword: Masonry systems; Seismic analysis; Mortarless block; Interlocking block; Finite element method 